\title{
A FUNÇÃO SOCIAL DA HIPOTECA NO PROCESSO DE CUMPRIMENTO DOS CONTRATOS DE FINANCIAMENTO IMOBILIÁRIO PARA AQUISIÇÃO DE MORADIA
}

\author{
THE SOCIAL FUNCTION OF THE MORTGAGE IN THE PROCESS \\ OF FULFILLING THE REAL ESTATE FINANCING CONTRACTS \\ FOR THE PURCHASE OF HOUSING
}

\author{
${ }^{1}$ Francisco Cardozo Oliveira \\ ${ }^{2}$ Gabriela Cristine Buzai
}

\section{RESUMO}

$\mathrm{O}$ artigo analisa a viabilidade de uma função social da hipoteca no processo de cumprimento dos contratos de financiamento imobiliário para aquisição de moradia, na realidade social e econômica brasileira. Discute-se o papel do contrato de financiamento imobiliário no sistema de crédito no atual contexto de globalização financeira, na perspectiva de uma premissa de processo de cumprimento de obrigações que tenha como relevante o equilibrio de direitos e obrigações e disposição de cooperação das partes para o adimplemento. Sustenta-se que a função social da hipoteca está inserida na dinâmica do processo de cumprimento das obrigações do contrato de financiamento imobiliário e pode ser modulada pelo caráter maleável do princípio da acessoriedade, inclusive no momento da execução da garantia. A metodologia utilizada é a dialética crítica.

Palavras-chave: Hipoteca, Moradia, Obrigação, Função social

\begin{abstract}
The article examines the feasibility of a social function of the mortgage in the process of fulfilling the real estate financing contracts for the acquisition of housing, in the social and economic reality. It discusses the role of the real estate financing business in the credit system in the current context of financial globalization, in the perspective of a premise of process of fulfilment of obligations you have as a relevant balance of rights and obligations and willingness of cooperation of the parties to the contractual obligations. Contends that the social function of the mortgage is entered in the dynamics of the process of fulfilment of the obligations of the mortgage contract and can be modulated by the malleable nature of the principle of acessoriedade, including at the time of execution of the guarantee. The methodology used is the critical dialectic.
\end{abstract}

Keywords: Mortgage, Housing, Obrigation, Social function

1Doutor emDireito pela Universidade Federal do Paraná - UFPR, Paraná, (Brasil) Emai: tutortreinamento@ gmail.com 2Mestre emDireito Empresarial e Cidadania no Centro Universitário Curitiba - UNICURITIBA, Paraná, (Brasil) 


\section{INTRODUÇÃO}

$\mathrm{O}$ artigo tem como objetivo analisar o papel da garantia hipotecária no processo de cumprimento das obrigações nos contratos de financiamento imobiliário para aquisição de moradia na realidade social e econômica brasileira.

Nesse sentido, defende-se a premissa de uma função social da hipoteca nesse tipo de contrato que cumpriria duas finalidades: a de assegurar o equilibrio de obrigações no processo de cumprimento das obrigações, que se estende até o momento da execução, no caso de eventual inadimplemento e a de assegurar o acesso a habitação para garantia do direito social constitucional à moradia.

Uma análise em que colocado como relevante a questão da funcionalização da hipoteca exige, necessariamente, levar em conta o contexto social e econômico em que inseridos o contrato e os contratantes e seus interesses. Deste ponto de vista, justifica-se identificar uma função social da hipoteca, no plano jurídico, uma vez considerado que a crise de 2008 que ainda produz efeitos no Brasil teve como elemento estrutural determinante formas de operabilidade nos mercados financeiros de títulos lastreados em garantias hipotecárias.

Pode-se dizer que a hipoteca permite articular mercado de crédito e mercado financeiro, na atualidade, de modo maximizar rentabilidade, em detrimento, muitas vezes, dos ganhos observados nos mercados de bens industrializados.

Um dos grandes anseios do indivíduo é possuir uma sua "casa própria", sendo que para isso, compromete grande parte de seus rendimentos para alcança-lo, o que inclusive, é incentivado pelo Estado, por intermédio dos inúmeros programas de financiamentos habitacionais identificados no decorrer dos anos, os quais, podem ter inúmeras alterações, porém, o objetivo é o mesmo, o de garantir que o indivíduo alcance o direito fundamental à moradia.

O problema a ser enfrentado diz respeito ao alcance da função social da hipoteca nos contratos de financiamento imobiliário, tendo-se em conta o pressuposto de acesso ao direito fundamental à moradia, tutelado pelo art. $6^{\circ}$ da Constituição da República.

Para tratar do problema, inicia-se a análise por uma perspectiva mais dogmática de estabelecimento das características dos contratos de financiamento imobiliário no ordenamento jurídico brasileiro. 
Na sequência, a análise se volta para a compreensão do processo de cumprimento das obrigações nos contratos de financiamento imobiliário, levando-se em conta a premissa fundamental de equilibrio das obrigações contratuais.

Por fim, discute-se o alcance da função social da hipoteca indicando-se as finalidades que ela contempla especificamente nos contratos de financiamento imobiliário para aquisição de moradia.

Para o desenvolvimento do estudo, adota-se uma metodologia dialética e crítica que une os três momentos da análise e que justifica as considerações finais.

\title{
1. CARACTERÍSTICAS DO CONTRATO DE FINANCIAMENTO IMOBILIÁRIO NA REALIDADE JURÍDICA BRASILEIRA
}

Os contratos bancários têm por finalidade intermediar o crédito. Assim com a visão introduzida pelo Código Civil de 2002, acerca da harmonização dos interesses individuais (autonomia de vontade) e sociais (função social), tais contratos devem observar o princípio da socialidade e as regras e princípios constitucionais (THEODORO JUNIOR, 2004, p. 37-38).

De acordo com Enzo Roppo (1988, p. 37-38), a liberdade de contratar na economia de mercado precisa considerar o contexto de vida das partes; nesse sentido, diz ele,

\begin{abstract}
A liberdade de contratar as segura também a "justiça” de cada relação contratual, em virtude da igualdade jurídica entre os contratantes. Mas desta forma esquece-se que a igualdade jurídica é só igualdade de possibilidades abstratas, igualdade de posições formais, a que na realidade podem corresponder - e numa sociedade divida em classes correspondem necessariamente - a gravíssimas desigualdades substanciais, profundís simas dis paridades das condições concretas de força econômico-social entre contraentes que detém riqueza e poder e contraentes que não dispõem senão de sua força de trabalho. O empresário com pleno controle do mercado de trabalho e o operário que, junto deste, procura emprego são juridicamente iguais, e igualmente livres - num plano formal - de determinar o conteúdo do contrato de trabalho. Mas é evidente (e a história de toda uma fase de desenvolvimento do capitalismo documenta-o de modo muitas vezes trágico) que o segundo, se não quiser renunciar ao trabalho, e, consequentemente, à sua própria subsistência, estará sujeito a suportar (pelo menos até que surjam adequadas providências "limitativas da liberdade contratual") todas as condições de contratação.
\end{abstract}

Como lembra Paulo Lobo, na sociedade de massas o contrato deixa de ser apenas instrumento de exercício de direitos para assumir a de instrumento de política econômica; assim, aumenta a importância do contrato ao mesmo tempo, diz ele, que entra em declínio a autonomia da vontade, que não é mais suficiente para explicar o arranjo de direitos e obrigações existentes entre as partes. Daí sustenta o próprio Paulo Lobo (1986, p. 17-24), que ocorre o fenômeno da despersonalização das relações jurídicas de massa. 
É nesse contexto, que se reafirma a necessidade de repersonalização do direito privado, e consequentemente, dos direitos contratuais, no sentido de recolocar em primeiro plano os interesses da pessoa, em detrimento de interesses essencialmente patrimoniais. Abre- se a perspectiva para a consideração da situação existencial da pessoa e da necessidade de titularização de direitos capazes de assegurar existência digna.

Sem ferir a finalidade principal do contrato, qual seja, sua função econômica, Humberto Theodoro Junior afirma que a função social deve caminhar harmoniosamente com as obrigações contratadas (2004, p. 97-114). Deve-se ter em vista, assim, que os contratos são instrumentos de jurisdicização do comportamento humano no campo econômico. Caberia à função social delimitar direitos e obrigações no contrato em torno das finalidades queridas pelas partes. Trata-se de compreender os contratos de financiamento imobiliário inseridos numa lógica de autonomia privada que, na esteira da concepção de Ana Prata (1980), permita juridicizar as atividades das pessoas, na vida em sociedade, de modo a reconhecer o direito de tutela a direito no plano do ordenamento jurídico.

Assim, as obrigações inseridas nos contratos de financiamento imobiliário observam uma premissa de reconhecimento que passa pela valoração do comportamento das partes durante a execução do contrato. Está em causa, portanto, uma perspectiva de valorização da boa-fé mensurada a partir do comportamento dos contratantes. A boa-fé, neste caso, deve ser compreendida segundo o sustentado por Judith Martins-Costa (2000, p. 402), dentro de uma perspectiva de ordenação unitária em que, diz ela:

\begin{abstract}
A noção de contato social - perspectivada como fattispecie por excelência do direito obrigacional - enseja a incidência, também graduada, da boa-fé objetiva, seja como função limitadora do exercício de direitos subjetivos, seja com a função criadora de direitos, deveres e pretensões que passam a integrar a relação obrigacional em seu dinâmico processar-se, compondo-a como uma totalidade concreta. Assim, vis ta a partir da pers pectiva ditada pela noção de contato social, a relação obrigacional não pode mais ser definida como uma soma ou composição "fechada" de direitos e deveres, mas como uma totalidade concreta, que não se confunde com os deveres (e poderes, ações, pretensões e exceções) que o vínculo abstratamente encerra.
\end{abstract}

O contrato de financiamento imobiliário, que tem por escopo assegurar acesso ao crédito de modo a possibilitar, naquilo que aqui interessa, a aquisição de habitação para moradia incorpora uma dinâmica de direitos e deveres que se objetivam à medida em que se desenvolve o processo de cumprimento das obrigações. Assim, direitos e obrigações no contrato sofrem os efeitos do contexto social e econômico em que inseridas as partes. Também o contrato de financiamento imobiliário deve estar revestido pelos valores da repersonalização e 
da garantia das necessidades existenciais da pessoa, notadamente porque mediante sua instrumentalização se objetiva o acesso ao direito à moradia. Manifesta-se, portanto, toda uma dinâmica no contrato de financiamento imobiliário a ser captada pelas cláusulas gerais de funcionalização do direito privado.

Do ponto de vista de uma racionalidade classificatória, o contrato de financiamento bancário, que em essência é um contrato de mútuo, se caracteriza como um contrato comutativo, porque no momento da contratação, as partes têm plena ciência de suas obrigações, vantagens e sacrifícios do negócio; bilateral, tendo em vista que envolverá duas partes na contratação; trata-se de uma obrigação de fazer, porque cabe à instituição financeira a obrigação de emprestar o dinheiro contratado para possibilitar a aquisição de bens; pode ser caracterizado como contrato de adesão pois não está aberto ao mutuário discutir as cláusulas contratuais, senão apenas aceita-las (AGUIAR JUNIOR, 2003, p. 13-33).

No contrato de financiamento bancário o objeto diz respeito a entrega de uma quantia em dinheiro, a qual fica atrelado ao investimento objeto da negociação, como no caso em análise, a habitação. Assim, segundo expõe João Batista Vasconcelos é possível caracterizar o contrato de financiamento bancário como nominado, bilateral, oneroso, consensual, comutativo, sinalagmático e de consumo (2013, p. 69).

$\mathrm{O}$ contrato de financiamento imobiliário assegura a aquisição de moradia. Em razão do caráter social do direito à moradia o contrato de financiamento imobiliário deve observar o princípio da proporcionalidade entre as prestações e a renda do mutuário (RIZZARDO, 2000, p. 117-123). Nesse sentido, o contrato de financiamento imobiliário deve ser visto na perspectiva da essencialidade dos contratos traduzindo a primazia dos valores existenciais.

Nessa perspectiva, Rosalice Fidalgo Pinheiro (2009, p. 118-122) esclarece que o paradigma da essencialidade observa um modo de contratação diferenciado para as mais diversas obrigações, considerados os direitos essenciais para a sobrevivência humana.

$\mathrm{O}$ direito à moradia se insere na perspectiva do mínimo existencial que remete às condições mínimas de dignidade e de sobrevivência da pessoa humana (PINHEIRO, 2009, p. 127-133). Nos contratos de financiamento imobiliário está em causa, de um lado direitos essenciais de sobrevivência da pessoa e de outro os interesses de ganhos no mercado financeiro; nesse contexto, é necessário observar o modo como a desigualdade social e material das partes pode determinar a maneira como se estrutura o processo de cumprimento das obrigações contratadas.

$\mathrm{Na}$ realidade brasileira, grande parte dos contratos de financiamento imobiliário utiliza da garantia da hipoteca para assegurar o cumprimento das obrigações a cargo do 
mutuário. Assim, a garantia hipotecária também participa do escopo da contratação de permitir acesso ao direito à moradia.

A importância da função social da garantia nos contratos de financiamento se situa em torno da operabilidade de tutelas no contexto do que João Batista Vasconcelos, indica de dilema entre a recuperação de crédito e a existência de vultosos saldos devedores, por ocasião da execução de dívidas (2013), que coloca em risco o exercício do direito à moradia por parte do mutuário.

O contrato de financiamento imobiliário, com garantia hipotecária, deve observar um processo de cumprimento das obrigações contratadas compatível com uma premissa de equilíbrio e de cooperação que esteja de acordo com a finalidade de assegurar acesso ao direito à moradia.

\section{A COMPREENSÃO DA PREMISSA DO PROCESSO DE CUMPRIMENTO DAS OBRIGAÇÕES NOS CONTRATOS DE FINANCIAMENTO IMOBILIÁRIO}

Uma vez verificada o objetivo dos contratos de financiamento imobiliário de propiciar acesso ao direito a moradia, resulta necessário em um primeiro momento estabelecer as premissas da ideia de processo de cumprimento das obrigações e seus escopos para, na sequência, estabelecer de que modo esse processo se articula nos contratos sob análise, de modo a determinar as finalidades de função social da hipoteca.

As noções de dever e de responsabilidade, assim como as faculdades e interesses já devem ser consideradas desde uma perspectiva de construção da socialidade. Nesse sentido, é necessário considerar, no plano social, o contexto socioeconômico da pós-modernidade e, no plano jurídico, a construção de uma dogmática pós-positivista.

Numa visão interdisciplinar e socioeconômica, o direito das obrigações e dos contratos regula a contratualidade e, consequentemente, confere segurança jurídica ao processo de trocas de mercadorias e serviços na economia de mercado.

Tratando-se o contrato de financiamento imobiliário de operação efetivada no mercado de crédito, é necessário entender o papel do crédito na economia globalizada; segundo Luiz Gonzaga Belluzzo (2014, p. 26-27), no mercado de crédito,

(...) os ganhos propiciados pela valorização da riqueza financeira dos mais abastados sustentaram o consumo conspícuo e, simultaneamente, facilitaram o crédito barato aos consumidores menos afortunados. O circuito de valorização da riquezadiferenciação do consumo dos ricos "obriga" as famílias de renda média e baixa a comprometer uma fração crescente de seus ganhos com o endividamento no afã de acompanhar novos padrões. No mundo em que mandam os mercados da riqueza financeira e a concorrência entre as grandes corporações, os cidadãos estão divididos entre vencedores e perdedores. Os primeiros, ao acumular capital financeiro, gozam 
do "tempo livre" e do "consumo de luxo". Os demais se tornam dependentes crônicos da obsessão consumista e do endividamento, permanentemente ameaçados pelo desemprego e, portanto, obrigados a competir desesperadamente pela sobrevivência.

O mercado de crédito, na atualidade, promove a ampliação do crédito e o endividamento de pessoas pobres e a conversão de dividas em títulos especulativos nos mercados, com o que está na origem das instabilidades e crises recentes, em que o financiamento para aquisição de imóvel ocupa papel central.

No plano jurídico, é necessário, portanto, formular os fundamentos do direito das obrigações capaz de manter a construção da socialidade a salvo dos efeitos nocivos oriundos da atual configuração econômica do mercado de crédito, naquilo que diga respeito aos financiamentos imobiliários.

Segundo Orlando Gomes, a ideia de obrigação constitui a base do direito e mesmo das ciências sociais, ressaltando que o direito das obrigações elaborado no sec. XIX, inspirado no Direito Romano e aperfeiçoado pela Escola das Pandectas, propiciou desenvolvimento econômico, mas também favoreceu o individualismo e o abuso econômico (2004). A preocupação foi a de conferir ao direito uma estrutura sistêmica composta por conceitos jurídicos tomados como realidades lógicas, sem relação com valores.

As mudanças sociais verificadas ao longo do séc. XX produziram efeitos nos fundamentos do direito das obrigações que, de uma perspectiva individualista, passou a adotar postulados em torno da busca de igualdade social, o que significou a adoção de limitações à liberdade de manifestação da vontade. $\mathrm{O}$ objetivo foi o de fazer um uso do direito comprometido com uma cosmovisão do homem e da vida e com o propósito de alcançar um mundo melhor e mais justo.

Com a consolidação da sociedade de massas da atualidade, o fundamento do direito das obrigações assimila o princípio de equilibrio das obrigações, ao mesmo tempo em que rompe com o princípio da intangibilidade do conteúdo do contrato. A teoria das bases do negócio jurídico, do abuso de direito, da aparência, assim como o conceito de impossibilidade econômica são utilizadas para justificar a exoneração do devedor de obrigações abusivas.

Portanto, na pós-modernidade, assimila-se a ideia de que a liberdade absoluta não existe, a liberdade se exerce na vida em sociedade. A ideia de pessoa dotada de vontade livre não é compatível com a premissa de uma vontade individual e de autonomia que sustenta os fundamentos do direito civil. 
A formulação de uma teoria geral do direito das obrigações pós-positivista, que seja capaz de compreender as finalidades e os valores integrantes da relação jurídica obrigacional no contrato de financiamento imobiliário para aquisição da moradia, precisa situar a pessoa no seu contexto social e econômico, porque somente desse modo será possível formular uma visão sistêmica dos institutos jurídicos que possa integrar, mediante o compreender dialético, sentido e realidade e permitir uma interpretação abrangente dos conceitos jurídicos, da lei e dos fatos.

Nesse sentido, o contrato de financiamento imobiliário para aquisição da moradia pode ser visto na perspectiva do direito civil constitucional, em que, de acordo com Pietro Perlingieri (2008), a ideia de direito subjetivo não pode mais ser concebida como expressão de um interesse individual protegido pelo ordenamento jurídico, mas um interesse que está inserido na "complexidade das situações subjetivas" que pressupõem poderes e deveres, que devem ser entendimentos de acordo com os princípios constitucionais.

O solidarismo deve ser entendido, segundo Jorge Mosset Iturraspe, como uma visão do direito mais preocupada com a pessoa e com valores comunitários, como reação ao patrimonialismo e ao individualismo, um pensamento que se articula em torno da ideia de um dever social de cooperação para atingir o bem comum.

No mesmo sentido, de acordo com Paulo Lobo (2011, p. 18), em termos de repersonalização do direito civil, a partir dos fundamentos constitucionais, a sistematização do direito das obrigações, afastou-se do paradigma liberal de prevalência dos interesses do credor e adotou o paradigma de equilibrio de direitos e deveres entre credor e devedor, numa dimensão de igualdade material, com base no princípio de solidariedade social.

Nesse contexto, o alcance e os efeitos do direito das obrigações exige fixar os diversos interesses em jogo na situação subjetiva e ponderar valores e finalidades, segundo o tipo de interesse a ser tutelado pelo ordenamento jurídico.

Em torno da ideia de processualidade poderia ser ressaltado que, na atualidade, embora não se possa negar que a relação jurídica obrigacional está destinada à satisfação do credor, é necessário enfatizar, como faz Marcelo Junqueira Calixto (2005, p. 1-28), o dever de cooperação do próprio credor para esse fim, o que conduz à premissa de que a obrigação configura uma relação de cooperação, em que inseridas as posições do devedor e do credor.

Além do conteúdo da relação jurídica, Fernando Noronha também considera elemento da obrigação a finalidade, ou seja, a função que justifica o reconhecimento e a tutela jurídica o que a torna correlata de uma função social das obrigações (2010). A finalidade da obrigação é a satisfação de um interesse que, contudo, ultrapassa da esfera individual como 
ressalta Fernando Noronha, na medida em que expressa a transferência de bens e produtos entre pessoas na vida social e econômica.

Pode-se afirmar então, na linha do sustentado por Clóvis do Couto e Silva (2013), que o contrato de se manifesta uma dinâmica constituída por um conjunto de atividades dirigidas para a finalidade do adimplemento.

No caso dos contratos de financiamento imobiliário para aquisição da moradia, esse conjunto de atividades que conduz ao inadimplemento engloba finalidades de funcionalização em que o equilibrio de obrigações está regulado pela finalidade de assegurar o acesso a habitação. O processo de cumprimento das obrigações no contrato de financiamento imobiliário inclui a garantia hipotecária, de modo que mesmo no momento da execução não está afastada a possibilidade de exame do alcance da cooperação e do equilibrio de obrigações tendentes a propiciar o adimplemento e, de consequência, a aquisição da moradia.

\section{A FUNÇÃO SOCIAL DA HIPOTECA NOS CONTRATOS DE FINANCIAMENTO IMOBILIÁRIO}

Como já sustentado, a função social é ela própria uma das finalidades das obrigações que não diz respeito apenas a interesses pessoais de credor e devedor, mas a interesses sociais inscritos na configuração da vida social e econômica. A função social assim como as finalidades e interesses têm uma componente dinâmica que não é inteiramente captada na perspectiva de análise de elementos estruturais da relação obrigacional.

Os conceitos jurídicos não se formam no vazio traduzido por uma consciência jurídica abstrata, que despreza o acontecer do mundo. $\mathrm{O}$ que constitui o conceito jurídico, em essência, encontra-se arraigado na realidade social e histórica. Importa mais o estudo empírico da função do que a analítica de categorias normativas, retomando em outro patamar a oposição entre positivismo e naturalismo (LOPES, 2014, p. 204).

São essas premissas metodológicas que devem balizar a análise da hipoteca e sua função social, tendo em vista que seria impossível analisar o instituto da hipoteca sem que realizada uma correlação entre história, economia e sociedade. Do jurista exige-se uma visão interdisciplinar, que the permite reconhecer os reflexos do fenômeno jurídico para além da esfera específica da juridicidade.

A análise da hipoteca precisa levar em consideração elementos históricos, econômicos e sociais da conformação jurídica dos diversos modelos de garantias. É 
imprescindível também a análise dos efeitos econômicos e sociais das práticas contratuais possibilitadas pelas espécies de garantias reais reguladas pelo ordenamento jurídico. $\mathrm{O}$ diálogo entre direito e economia, nesta matéria, assim como em outras áreas, é fundamental para a correta operacionalidade das garantias reais.

A função social no contrato deriva do modo como articulados os interesses na contratação, de modo que não se trata de opor funcionalização ao querido pelas partes; antes a funcionalização está inserida na dinâmica dos interesses presentes na contratação. Não se trata, portanto, de negar o caráter econômico e jurídico da hipoteca; a função social da hipoteca resgata o valor do instituto na estruturação do mercado de crédito voltado para o financiamento de moradias, tanto mais necessário diante dos efeitos da crise de 2008 nos mercados imobiliários.

Parte-se de duas ordens de investigações para o estudo atual da situação da hipoteca, sendo que a primeira vai situar a hipoteca no quadro de funcionalização do direito privado, enquanto a segunda, especifica se a hipoteca deve ser incluída na problemática da funcionalização da propriedade ou se, diferentemente, ela deve seguir o princípio de funcionalização dos contratos; existem pontos de contato entre uma funcionalização e outra que precisam ser reconhecidas à luz do processo de aplicação do instituto e dos elementos integrantes da situação fática a ser tutelada.

Entretanto, a ideia de complementaridade funcional ganha maior intensidade científica quando verificado que contrato e propriedade são os dois institutos básicos que asseguram o processo de trocas no mercado, no modelo econômico do capitalismo. A hipoteca, desta forma, como não poderia deixar de ser, também está sujeita ao princípio de funcionalização que toma a feição hỉbrida da função social dos contratos e da função social da propriedade.

O contrato e a propriedade são instrumentos jurídicos com escopo definido de viabilizar a ordem econômica e social fundamentada na economia de mercado. Mas, se por um lado, contrato e propriedade, do ponto de vista jurídico, servem à finalidade de conformar a economia de mercado, nada impede que, por outro, em razão da funcionalização e da premissa de que o direito, como sistema, não precisa, necessariamente, mimetizar a todo instante as regras do mercado e do modelo econômico que lhe é subjacente, eles possam ser tecnicamente instrumentalizados para operar o acesso a bens nos limites em que a apropriação deles, como condição de sobrevivência, na sociedade capitalista, se revela limitada e excludente. 
Neste contexto, o papel da hipoteca é o de facilitar a celebração de contratos, o acesso a crédito e financiamento e a aquisição da propriedade de bens por parte de pessoas e famílias de renda reduzida ou de pequenos e médios empresários. O acesso ao crédito, a multiplicação de proprietários e a de consumidores sem dúvida alguma são atividades indispensáveis para o incremento do desenvolvimento social e econômico e, como sustenta Axel Honneth (2014), para a garantia da liberdade social da pessoa.

Vista na perspectiva de acesso ao crédito e à moradia, a hipoteca, inexoravelmente, incorpora os elementos finalísticos dos princípios de funcionalização, que traduzem o fundamento do que poderia ser reconhecido como o primado de justiça na economia de mercado de redução de desigualdades e de busca de homogeneização na apropriação dos bens produzidos em sociedade. Como se verifica, resulta viável sustentar uma função social da hipoteca, que permita assegurar acesso ao crédito e ao direito à moradia, no contexto de contratos de financiamento imobiliário.

Os efeitos da função da garantia hipotecária podem ser melhor avaliados ás luz dos princípios reguladores da hipoteca, em especial o princípio da acessoriedade. Segundo o princípio da acessoriedade, a garantia da hipoteca está atrelada à relação jurídica contratual de natureza econômica e creditícia, com a finalidade de garantir o cumprimento da obrigação principal. Conforme advertem Harry Westermann e Outros, a acessoriedade não existe como conceito absoluto, com um conteúdo prefixado; deve-se observar o contexto da relação jurídica em que ela opera efeitos (1998).

Para harmonizar o princípio da acessoriedade com a natureza do sistema de registros públicos, segundo Clóvis do Couto e Silva (1997, p. 137-176), o BGB adotou como regra a hipoteca de tráfico e não a de garantia; diz ele que a eficácia do registro de imóveis não “dominifica” a relação creditícia tornando-a oponível a terceiros; no sistema germânico, a publicidade diz respeito apenas ao ônus real inscrito e não ao crédito ao qual acedeu; as regras a respeito da extinção dos créditos não são atingidas pelo sistema registral, de modo que, solvida a dívida, não adquire o terceiro a posição de credor; ele torna-se titular da garantia real por força da constitutividade do registro.

Segundo afirma Rosa Maria A. Ríos (2006, p. 263-281), no exame do direito espanhol, adotou-se uma premissa de acessoriedade maleável, em que a hipoteca pode estar funcionalmente atrelada a obrigação certa no momento de constituir-se, mas, ao longo do processo de cumprimento das obrigações, ela pode substantivar-se e desligar-se daquela 
obrigação, sem perder a função de garantia, ou ainda necessitar de uma obrigação para ser executada (casos de hipoteca de dívida futura).

Posta a questão nestes termos, a funcionalização opera uma espécie de modulação da incidência do princípio da acessoriedade na garantia hipotecária de modo a harmonizar as situações jurídicas. Uma maior flexibilização da garantia hipotecária tende a adotar o modelo de hipotecas de tráfico, em que o princípio da acessoriedade cede frente à necessidade de registro. Em torno dessa questão, Beatriz Sáenz de Jubera Higuero (2008, p. 301-308) trata do que ela denomina de funcionalidade do princípio da acessoriedade com a introdução das hipotecas de tráfico na Espanha (Ley 41/2007).

Já na rigidez do modelo de hipoteca em garantia o princípio da acessoriedade mantém a objetividade da relação entre a obrigação creditícia e a garantia hipotecária. Para Carlos de Cores e Enrico Gabrielli (2008, p. 32), o princípio da acessoriedade incorpora uma dimensão funcional da hipoteca diretamente ligado à propriedade imobiliária com função de garantia, de modo a evitar o enriquecimento do credor à custa do devedor. O princípio da acessoriedade, desse modo, contempla uma plasticidade capaz de operar internamente à relação jurídica obrigacional as finalidades de função social da hipoteca.

Resulta evidenciado assim que a hipoteca comporta uma espécie de funcionalização que pode ser operacionalizada pelo princípio da acessoriedade.

A funcionalização da garantia hipotecária assume papel determinante no acesso moradia na realidade brasileira. O Brasil sofre de carência de moradia para pessoas de baixa renda. A solução desse problema de carência de moradia se viabiliza pela intermediação do mercado de construção civil, mediante financiamento com recursos públicos. O incentivo governamental ao mercado de construção civil atua para reduzir o déficit de moradias e para gerar emprego e dinamismo econômico. Contudo, o preço das moradias acaba elevado influenciado pela dinâmica de valorização e escassez da terra nas cidades (OLIVEIRA, 2009, p. 131-149).

Nos momentos de crise, quando reduzido o volume de financiamento público, o mercado da construção civil não atua para suprir a demanda com recursos provados, de modo que se acentua a falta de atendimento das necessidades de moradias populares. Assim, no Brasil, o Estado desempenha um papel fundamental na alocação de recursos, por intermédio do mercado de construção civil, para assegurar a efetividade do direito fundamental à moradia, em especial para as pessoas de baixa renda. 
A disponibilização de recursos financeiros para a construção de moradia intermediada pelo mercado se apoia no instituto da hipoteca. Desse modo, a hipoteca desempenha uma funcionalidade diretamente atrelada à efetividade do direito à moradia.

Em torno da hipoteca se articula uma espécie de função social cuja finalidade se objetiva pelo acesso ao direito à moradia. Nesse sentido a função social da hipoteca pode atuar para fortalecer o mercado de crédito mediante a ampliação da disponibilidade de financiamentos; por outro lado, a função social da hipoteca, que se insere no processo de cumprimento do contrato de financiamento imobiliário, pode produzir efeito no modo de execução da garantia, nas situações de inadimplemento pelos adquirentes de imóveis para o atendimento das necessidades pessoais de abrigo; neste último caso, a funcionalização serviria para resgatar o equilibrio das obrigações no contrato, mediante a modulação dos seus efeitos pelo caráter maleável do princípio da acessoriedade.

E, nesse sentido, a funcionalização da hipoteca carrega componentes de um princípio fraterno, de encontro do outro na vida em sociedade e de garantia de efetividade do direito social à moradia na realidade brasileira.

\section{CONSIDERAÇÕES FINAIS}

A análise evidenciou que a solução do problema proposto de investigar o alcance da função social da hipoteca nos contratos de financiamento imobiliário voltados para assegurar o acesso à moradia passou por três momentos: o primeiro momento de fixação dos pressupostos dogmáticos dos contratos de financiamento imobiliário voltado para assegurar o direito à moradia; o segundo de compreensão do processo de cumprimento das obrigações e de seus efeitos nos contratos de financiamento imobiliário; e o terceiro de objetivação das finalidades de função social da hipoteca nos contratos de financiamento imobiliário para aquisição de moradia.

A inter-relação entre esses três momentos, permite sustentar que os contratos de financiamento imobiliário estão inseridos na dinâmica dos mercados de crédito, que hoje potencializam riscos de endividamento dos mutuários, com reflexos na garantia do mínimo existencial representado pela possibilidade de privação do acesso à moradia.

$\mathrm{O}$ incentivo realizado pelo Estado para garantir o direito fundamental à moradia é algo visível no decorrer dos anos, bem como sua tutela na proteção do consumidor para com as instituições financeiras, muito embora, a necessidade de amparo seja constante e a 
funcionalização da hipoteca seja algo iminente, necessário de ser discutido e aplicado, tendo em vista a grande repercussão no direito imobiliário e bancário.

Também ficou evidenciado que os contratos de financiamento imobiliário, com garantia hipotecária, observam um processo de cumprimento das obrigações que contém uma dinâmica de equilíbrio e de cooperação entre as partes na direção do adimplemento e que produz efeitos inclusive nas situações de execução da garantia.

Finalmente, a análise evidenciou que é viável a admissão de uma função social da hipoteca nos contratos de financiamento imobiliário, em que as finalidades de funcionalização se dirigem para assegurar o acesso à moradia e podem ser operadas mediante a concepção de um caráter maleável do princípio da acessoriedade que deve modular o equilibrio de obrigações contratadas.

A função social da hipoteca capaz de assegurar a dinâmica de cumprimento das obrigações contratadas no contrato de financiamento hipotecário pode constituir-se no instrumento que, desde o sistema jurídico, opera efeitos, para conferir segurança jurídica ao mercado imobiliário e minimizar os efeitos de crises sociais e econômicas, com prejuízos diretos para as pessoas necessitadas de moradia e de vida digna na realidade social e econômica brasileira.

\section{REFERÊNCIAS BIBLIOGRÁFICAS}

AGUIAR JUNIOR, Ruy Rosado. Os contratos bancários e a jurisprudência do Superior Tribunal de Justiça. Brasîlia: CJF, 2003.

BELLUZZO, Luiz Gonzaga. O capital e suas metamorfoses. São Paulo: Editora Unesp, 2013.

CALIXTO, Marcelo Junqueira. Reflexões em torno do conceito de obrigação, seus elementos e suas fontes. In Obrigações - Estudos na perspectiva civil-constitucional. TEPEDINO, Gustavo (Coord). Rio de Janeiro: Editora Renovar, 2005, p. 1-28.

CORES, Carlos de; GABRIELLI, Enrico. El nuevo derecho de las garantias reales: Estudio comparado de las recientes tendencias en materia de garantías reales mobiliarias. Buenos Aires: Editorial Zavalía, 2008.

GOMES, Orlando. Obrigações. 16. ${ }^{\text {a }}$ ed., Rio de Janeiro: Editora forense, 2004.

HIGUERO, Beatriz Sáenz de Jubera. Relación entre el crédito y la hipoteca: alcance del principio de accesoriedad. Madrid: Colegio de Registradores de la Propiedad y Mercantiles de España. 2008. 
HONNETH, Axel. Luta por reconhecimento: a gramática moral dos conflitos sociais. 2. ${ }^{a}$ ed., São Paulo: Editora 34, 2009. 2014 .

El derecho de la libertad: esbozo de una eticidad democrática. Madrid: Katz Editores,

LOBO, Paulo Luiz Neto. Direito civil - obrigações. 2. ${ }^{\text {a }}$ ed., São Paulo: Editora Saraiva, 2011. O contrato - exigências e concepções atuais. São Paulo: Editora Saraiva, 1988.

LOPES, José Reinaldo Lima Lopes. Naturalismo jurídico no pensamento brasileiro. São Paulo: Editora Saraiva, 2014.

MARTINS-COSTA, Judith. A boa-fé no direito privado. São Paulo: Editora Revista dos Tribunais, 2000.

NORONHA, Fernando. Direito das obrigações. 3. a ed., São Paulo: Editora Saraiva, 2010.

PINHEIRO, Rosalice Fidalgo. Contratos e direitos fundamentais. Curitiba: Juruá, 2009.

OLIVEIRA. Francisco Cardozo. Direito à cidade: moradia, atividade empresarial e sustentabilidade. Revista Jurídica. Curitiba: Unicuritiba, no 23, 2009.

PERLINGIERI, Pietro. O direito civil na legalidade constitucional. Rio de Janeiro: Editora Renovar, 2008.

PRATA, Ana. A tutela constitucional da autonomia privada. Coimbra: Editora Livraria Almedina, 1980.

RÍOS, Rosa Maria A. Aspectos críticos en la estructura de la hipoteca inmobiliária. Madrid: Editorial Dykinson, 2006.

RIZZARDO, Arnaldo. Contratos de crédito bancário. $5^{\mathrm{a}}$ ed. rev. atual. e ampl. São Paulo: Revista dos Tribunais, 2000.

ROPPO, Enzo. O contrato. Coimbra: Almedina, 1988.

SALLES, Raquel Bellini de Oliveira. O desequilibrio da relação obrigacional e a revisão dos contratos no Código de Defesa do Consumidor: para um cotejo com o Código Civil. In: TEPEDINO, Gustavo (Coord.). Obrigações: estudos na perspectiva civil-constitucional. Rio de Janeiro: Editora Renovar, 2005.

SILVA, Clóvis V. do Couto e. A hipoteca no direito comparado. In: FRADERA, Vera Maria Jacob de (Org.) O direito privado brasileiro na visão de Clóvis do Couto e Silva. Porto Alegre: Livraria do Advogado Editora, 1997.

2013.

A obrigação como processo. $1 .^{\mathrm{a}}$ ed., $8 .^{\mathrm{a}}$ reimpressão. Rio de Janeiro: Editora FGV,

THEODORO JUNIOR, Humberto. O contrato e sua função social. Rio de Janeiro: Forense, 2004. 
VASCONCELOS, João Batista. Função econômica dos contratos de financiamentos imobiliários e o direito fundamental à moradia. Dissertação (Mestrado em Direito Econômico). Universidade Federal da Paraíba - UFPB, João Pessoa, 2013.

WESTERMAN, Harry; WESTERMANN, Harm Peter; GURSKY, Karl-Heinz; EICKMANN, Dieter. Derechos reales. 7. a ed., Madrid: Fundación Cultural del Notariado, 1998. 